UDC $613+316.62$

\title{
METHODICAL QUESTIONS ON ASSESSMENT OF RISK ASSOCIATED WITH BEHAVIORAL FACTORS’ IMPACT ON POPULATION HEALTH*
}

\section{N.A. Lebedeva-Nesevrya}

FBSI "Federal Scientific Center for Medical and Preventive Health Risk Management Technologies", 82 Monastyrskaya St., Perm, 614045, Russian Federation

The study offers an algorithm and methods for semi-quantitative assessment of health risk associated with impact of behavioral factors that have scarce data for quantitative parametrization of the "factor - response" relation. Some of these factors include, first of all, irresponsible medical and hygienic behavior, violations of work and rest, sleep and wakefulness schedule. It was shown that the semi-quantitative risk assessment assumes the development of private mark scales for each estimated behavioral factor, as well as a choice of an integration way of scores, a choice of a way for establishing the negative effects' severity, formation of risk matrix. For example, the factor "irresponsible health behavior" demonstrates the method of the mark characteristics of the risk taking potential of separate risk components to be used in calculating of the individual and integrated indexes of health deterioration probability. The following components have been taken into account: a) timeliness of visiting a doctor, $b$ ) the practice of preventive examinations, $c$ ) compliance (commitment to the treatment appointed by a doctor), d) reception of medicines without appointment of the doctor, e) the request for the recommendation of medicines and methods of treatment to someone, except the doctor. The study offers a logical scheme of the behavioral risk factor analysis at the individual level for using on a stage of the exposure evaluation. It was shown that the tools used for exposure characterization must assume the possibility for assessment of the typicality and stability of behavioral patterns realized by individuals or a group. It is recommended to apply the matrix for semi-quantitative assessment of health risks associated with the activity of behavioral factors. The matrix combines two types of descriptors that both characterize a semi - quantitative probability assessment and assess the adverse effect severity.

Key words: health risk, semi-quantitative risk assessment, behavioral factors, coefficient of negative effects weight, exposure assessment, risk matrix.

Prevention of the risks associated with individual health habits is an important question. More than half $(63 \%)$ of the death cases globally are caused by non-infectious diseases determined by the behavioral risk factors, particularly, smoking, unhealthy eating habits, insufficient physical activity, and alcohol abuse [14].

Modifiable behavioral risk factors are major contributors to adolescent morbidity and mortality worldwide [5]. Along with the family lifestyle, they determine for the most part the state of health of the Russian children and adolescent [9].

The methodology of health risk analysis, including risk assessment, information on risks, and risk management that integrates, in addition to traditional chemical agents, the factors of microbial nature, lifestyle, etc. is the most appropriate tool to address the problems of monitoring, assessing and forecasting changes in health [1].

Assessment of the risks associated with the impact of behavioral factors on individual health, includes determination of the probability of negative health changes caused by the impact factors related to the behavior of an individual within a certain time period [2]. It is used to a) determine the priority factors that most influence the effectiveness of public health management; $b$ ) plan the measures to minimize the loss of human capital associated with risk-prone health behavior; c) predict the medical and demographic situation in the territory; d) identify the main contingent of risk and the development of social and preventive programs aimed to prevent the damage associated with low self-preservation behavior.

Results of the assessment of the health risks generated by specific behavioral practices (smoking, alcohol abuse, poor diet, physical

(C) Lebedeva-Nesevrya N.A., 2016

Lebedeva-Nesevrya Natalya Aleksandrovna - the doctor of sociological sciences, the associate professor, the head of the laboratory of the social risks analysis methods (e-mail: natnes@ fcrisk.ru; phone: 8 (342) 237-25-47).

* Article is prepared with financial support of the Russian humanitarian scientific fund (the project No. 16-16-59007, the head is N.V. Zaitseva). 
inactivity, etc.) can be used to develop and implement individual disease prevention programs through the network of public health centers, as well as general practitioners, shop physicians and pediatricians.

In Russia, there have been a lot of studies on the assessment of the quantitative risk associated with such behavioral factors as alcohol consumption, smoking, low levels of physical activity and poor nutrition [4]. However, some important behavioral risk factors need further research to establish the connection with health disorders and, accordingly, to quantify the risk of their occurrence. In these cases it seems appropriate to carry out a semi-quantitative or qualitative risk assessment.

Improvement of methodical approaches to the assessment of the risks associated with the impact of behavioral factors on health, for which a quantitative risk assessment is not possible, is the purpose of this work.

Despite the differences in the source information and approaches to its extraction, quantitative, semi-quantitative and qualitative risk assessment suggests the implementation of four interrelated steps: 1) hazard identification, 2) assessment of the "factor - effect" relationship, 3) exposure assessment, 4) risk characterization (Figure 1).

Hazard identification is the first step aimed to generate a complete list of potential hazards or levels of the factors (hazards) that can cause individual (group of people) health disorders; establish the critical organs and systems or types of health problems that can be expected; identify the study group, exposed and forming exposure scenarios (ie the conditions which may result in health disorders). The main methods used during hazard identification within the semi-quantitative and qualitative health risk assessment, include static analysis, meta-analysis of the results of scientific research, ordering, directed case studies.

The factors that should be included in the risk assessment procedure, are determined by the goals and objectives of a particular survey.

For example, in the United States, there is a national system that studies behavioral risk factors to health (since 1984) (The Behavioral Risk Factor Surveillance System). With the help of a telephone survey (annual volume of the sample - More than 400 thousand people in all the 50 states, including the District of Columbia and island areas) - data is collected on the prevalence of health risk factors related to a particular way of life. Some of these factors include socio-demographic characteristics of the respondents - gender, age, race, income level, marital status, etc. Also, they include various aspects of self-preservation behavior: physical activity, sleep characteristics, smoking, alcohol consumption, immunizations (for example, vaccination against influenza), seat belt use, physician visits (including the frequency of mammography, screening for cervical cancer, prostate cancer and colorectal cancer, testing for HIV / AIDS), the use of salt in the diet, sexual behavior. Additionally, they include the social and psychological contexts of life of an individual: stressors and availability of emotional support, life satisfaction $[12,16]$.

In Russia, there are no systematic studies of behavioral health risk factors at the national level. Some conclusions about the Russian lifestyle that determines the health status can be made based on the data of "the monitoring of the economic situation and public health by the Russian Higher School of Economics", conducted annually since 1995 by the National Research University - Higher School of Economics and CJSC "Demoscope" with the participation of the University of North Carolina at Chapel Hill (USA) and the Institute of Sociology of the Russian Academy of Sciences [6]. As part of the monitoring, the respondents are asked questions about their professional activities, health behaviors (including frequency of treatment to the doctor), smoking, drinking alcohol, diet, and the level of physical activity.

A wider range of behavioral risk factors is analyzed in the framework of private research or local samples. For example, in the study of the health factors that impact cancer survivors the following factors are taken into account: behavior in the sun (sun protection behaviors) [13], analysis of behavioral determinants of obesity - duration of watching television and using the computer [16]; and exposure to passive smoking when assessing the risk of respiratory diseases [15].

The most important behavioral factors of health risk that cannot be evaluated within the framework of quantitative procedures are: 1) irresponsible medical behavior, 2) irresponsible health behavior, 3) poor work and rest / sleep and 
wakefulness balance, 4) failure to comply with the rules of personal and household hygiene.

During a semi-quantitative or qualitative risk assessment at the "factor-effect" assessment stage, it is sufficient to know that the behavioral factors affect health and the more they are expressed, the

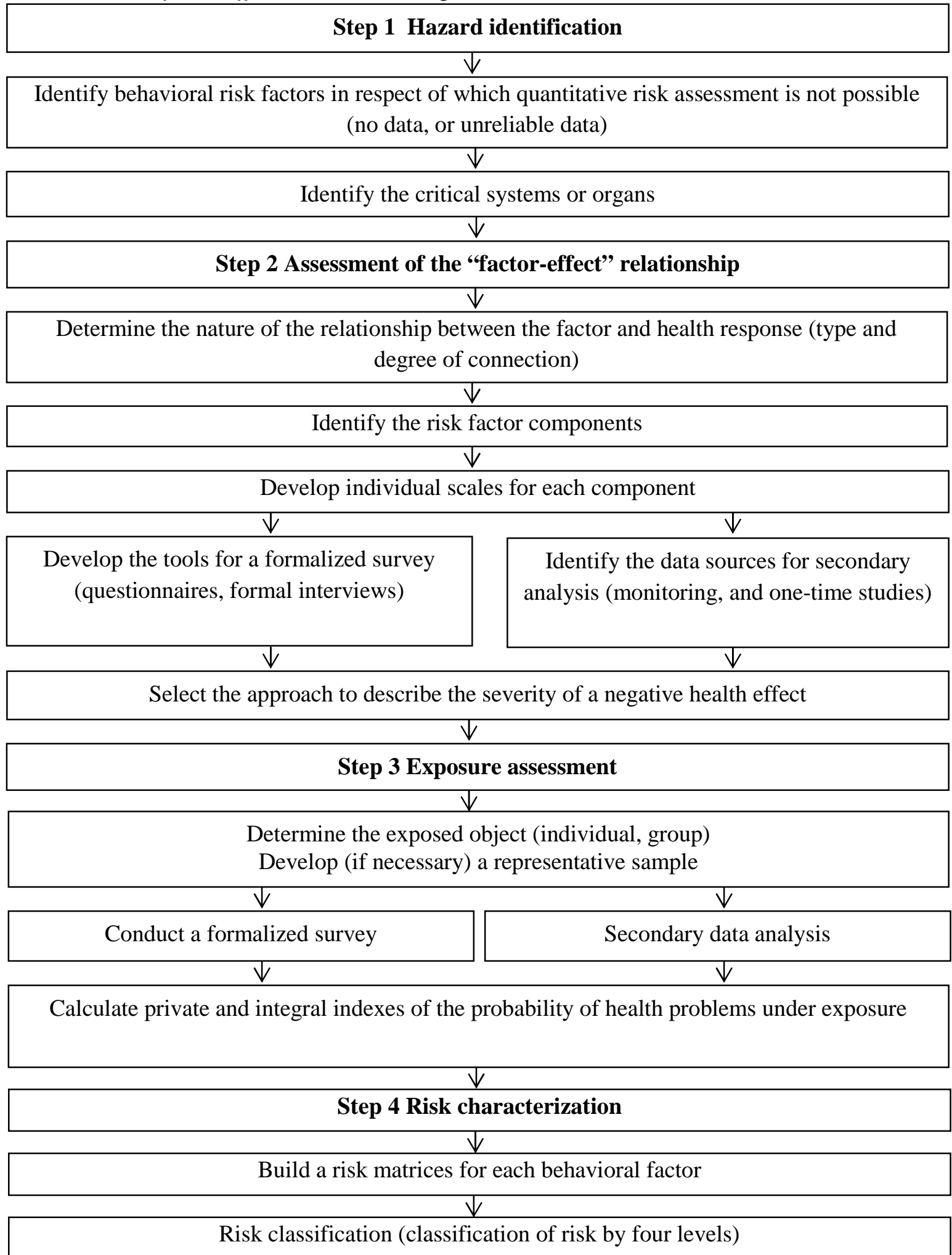

Figure 1 - Algorithm for semi-quantitative risk assessment of the impact of behavioral factors on public health 
more expressed is a health problem. For example, MU Surmach [8] proved that a low level of selfpreservation preventative activity of women before and during pregnancy (behavioral factors) adversely affects the health of a newborn (effect). In particular, it was found that among women who had undergone a full pregravid training, the percentage of intrauterine infection was significantly lower than among those who did not prepare for pregnancy ( $0.2 \%$ vs $4.6 \%$, respectively). These data may form the basis for a qualitative assessment of the risk associated with the effect of a woman's preventive activity on a newborn's health. The most important behavioral health risk factors, which cannot be evaluated within the framework of quantitative procedure, include: 1) irresponsible medical behavior, 2) irresponsible hygienic behavior, 3) poor work/rest or sleep/wakefulness balance, 4) failure to comply with the rules of personal and household hygiene.

A significant issue at the "factor-effect" assessment stage is fluctuating probability of negative effects realized subjectively. It is common to identify The three (low, medium and high) to five (very low - an event almost never happens; low - an event is rare; medium - probability of an event about 50\%; high - an event is likely to occur; very high - an event is almost certain It happens) probability levels.

When using behavioral risk factors to assess the probability of a negative effect, it is advisable to use a probability assessment matrix, including a list of the risk factor components, a qualitative assessment of each of the components (defined in the formal survey, for example - the survey), as well as a quantitative assessment of each component in points.

For example, the structure of the "medical behavior" factor can be viewed as comprising a) timely doctor's appointment, b) routine medical check-ups, c) compliance with the treatment, d) medication without a doctor's prescription, d) seeking recommendations on medicines and treatments from someone other than a doctor. "Risk-prone" content (the probability of adverse effects) of each component is determined by the results of individual surveying. So, if an individual visits a doctor at the first symptoms, the risk-content of the first component of the "medical behavior" factor evaluates to 0 if a health care individual recourse only if the manifestation of severe symptoms of the disease 1 point, and if you never go to the doctor - in 2 points. So, if an individual goes to the doctor at the first symptoms, the risk-content of the first component of the "medical behavior" factor equals 0 points. If an individual goes to the doctor only at serious symptoms, then it equals 1 point And if (s)he does not go to the doctor at all, then it equals 2 points.

For each component of the behavioral risk factors, it is possible to calculate partial index of the probability of disorder of a specific system $\left(I_{\mathrm{\Psi}}\right)$ :

$$
I_{\mathrm{\Psi}}=\frac{n}{n_{\max }}
$$

where $n$ represents the points corresponding to a particular expression of a component, $n_{\max }-$ represents the points corresponding to the maximum expression.

For each factor, it is possible to calculate the integrated index of the probability of disorder of a certain system $(I)$ :

$$
I=\frac{I_{\mathrm{u}}^{a}+I_{\mathrm{u}}^{b}+\ldots+I_{\mathrm{u}}^{z}}{m}
$$

where $I_{u}^{a}$ - individual probability index of a disorder, $m$ - the number of components of the risk factor.

The values of individual and complex indexes range from 0 to 1 , and are ranked according to the following scale: a) from 0 to 0.3 - low probability, and b) from 0.31 to 0.6 - medium probability, c) 0 , 61 to 1 - high probability.

For this procedure, it is essential to establish the severity of a adverse effect, i.e. the severity of a health disorder. To solve this problem, it is possible to use a medical criteria approved by the RF Health and Social Development to determine the severity of damage caused to health [3], that categorizes health disorders as heavy, moderate, and mild. There are alternative approaches to the assessment of the severity of adverse effects. Thus, M.U. Tsinker et al. [10] suggest using expert estimates based on the method of median ranks to determine the severity rate. As a result, 200 diseases that represent certain classes of diseases (formed on the basis of ICD-10), were attributed severity coefficients between 0.1 and 1. It is also possible to determine the diseases of mild, moderate, and high severity using the cases of diseases and death cases due to these diseases. By the value of the quotient of the number of deaths to the number of diseases (cases/thousand population), the entire set of values is divided into the three groups using «natural breaks» [7]. 
The purpose of exposure assessment is to determine individual susceptibility to particular behavioral risk factors or to establish the prevalence of this factor in the study group. To assess exposure to behavioral risk factors, it is possible to use a secondary analysis of the results of sociological research or previous studies. For semi-quantitative risk assessment, it is recommended to conduct research in the quantitative tradition using polling method, for example - by distributing questionnaires and conducting formal interviews.

Research tools help get an idea about the real impact of behavioral factors, and evaluate the commonness and stability of behavioral patterns used by an individual or a group.

A behavioral factor is understood as a sustainable combination of behavioral manifestations typical of an individual or a group. Pattern commonness is understood as its specificity to a given individual over a long period. The structure of the analysis of behavioral health risk factors in the framework of empirical sociological research for hazard identification purposes is presented in Figure 2.

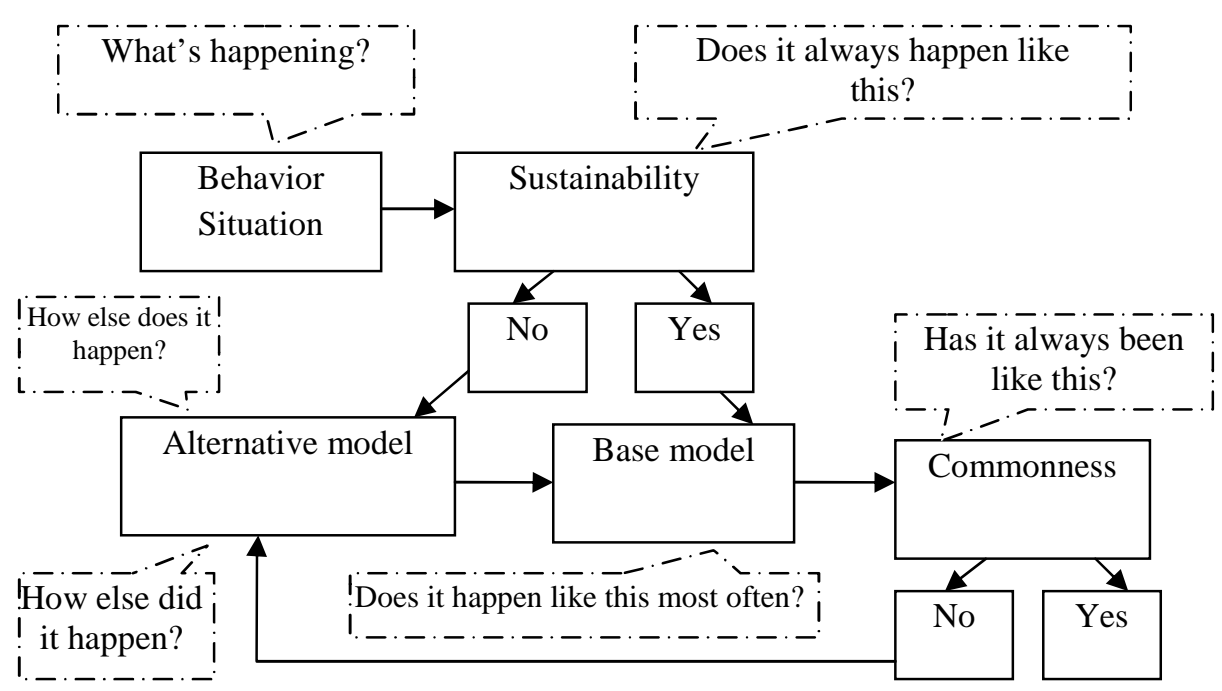

Figure 2 - The structure of the analysis of behavioral health risk factors on the individual level for the purposes of health risk assessment

Let us explain the above structure by the example of the factor "irresponsible medical behavior." At the first stage, a particular behavior of an individual is determined in relation to that factor. The frequency of doctor's visits for routine check-ups are determined as well as the main reasons for doctor's visits, compliance with the designated medical treatment, etc. Survey tools can include the following questions: "How often do you go in for a routine check-up by your own initiative? ","When and did you see a doctor last time?", "Are you taking any antibiotics without a prescription?" To assess predisposition to selftreatment, the following questions can be asked: "When feeling unwell, some people prefer to immediately consult your doctor, and refer to selftreatment only as a last resort. Others, however, prefer to be treated on their own, and only in extreme cases go to the doctor. Which group do you refer yourself to?"

To understand how the risks associated with irresponsible medical behavior are developed, as well as for in-depth risk analysis, the following questions can be asked: "In what situations do you consider seeing a doctor?" "Do you go to the doctor even when you do not feel acute pain?" "Do you recommend any medication to your friends and acquaintances?"

The second step is to establish the persistence of these behavioral manifestations in order to identify the basic behavioral patterns with regard to medical activity. To do this, the respondents are asked, for example: "Do you always go to the doctor in case of emergency?", "Do you always complete the course of treatment?"

The commonness of a behavioral pattern in relation to medical activity at the moment of the survey is determined by asking the following questions: "Have you had periods in your life when you did not go to the doctor at all?" and "Have you had periods in your life when you preferred selftreatment?" If it is determined that a respondent has not always displayed the type of behavior in regards to risk factors, which (s)he is displaying at the moment, then it is needed to obtain a complete 
description of those behaviors that were displayed previously.

At the risk characteristics stage, when conducting a semi-quantitative assessment of the risks associated with the effect of behavioral factors, the risk level is not calculated, but it is categorized using the risk assessment matrix (see Table below) that combines two types of descriptors - describing a semi-quantitative assessment of the probability and assessing the severity of the adverse effects.

A matrix for a semi-quantitative assessment of the risks associated with the effect of behavioral factors

\begin{tabular}{|l|c|c|c|}
\hline \multirow{2}{*}{$\begin{array}{c}\text { Probability of an adverse } \\
\text { effect }\end{array}$} & \multicolumn{3}{|c|}{ Severity of a health disorder } \\
\cline { 2 - 4 } & Mild & Moderate & High \\
\hline Low (I $\leq 0.3)$ & Megligible (I) & Moderate (II) & Very high (III) \\
\hline Medium $(0,3<\mathrm{I} \leq 0.6)$ & Moderate (II) & High (III) & Very high (IV) \\
\hline High (I $>0.6)$ & Moderate (III) & Very high (IV) & (IV) \\
\hline
\end{tabular}

With the use of the above risk assessment matrix, based on the combination of the three probability levels of health problems and the three severity levels, it is possible to define four risk levels associated with behavioral factors: negligible, moderate, high, and very high.

Conclusions. Assessment of the risks associated with the impact of behavioral factors on health, may be carried out using qualitative, semiquantitative and quantitative methods. When numerical data is needed to express the hazards and parameterize their connection to the health responses, the methods of qualitative and semiquantitative evaluation can be used. Their main task is to study the transformation of individual behavior strategies, establishment of priority activities to inform the population about the risks associated with the implementation of poor selfpreservation behavior.
Semi-quantitative risk assessment involves the development of an individual point-based scale for each of the assessed behavioral factors, selection of the method to integrate the score-based evaluations, selection of the method to establish the severity of adverse effects, and generation of the risk matrix.

Semi-quantitative evaluation of health risk is based on the transition from the qualitative and quantitative characteristics of the severity of behavioral factors to scoring. It can be used in relation to such factors as irresponsible medical and hygienic behavior, poor work/rest or sleep/wakefulness balance, and several others. With regard to active and passive smoking, alcohol consumption and drug use, physical inactivity, and malnutrition, it is recommended to carry out a quantitative health risk assessment.

\section{References}

1. Zaitseva N.V., May I.V., Shur P.Z. Analiz riska zdorov'ju naselenija na sovremennom jetape [Analysis of health risk to population at the present stage]. Zdravoohranenie Rossijskoj Federacii, 2013, no. 2, pp. 20-24. (in Russian.

2. Zaitseva N.V., Shur P.Z., Kiryanov D.A., Chigvintsev V.M., Dolgikh O.V., Luzhetskiy K.P. Metodicheskie podhody $\mathrm{k}$ raschetu verojatnosti negativnyh otvetov dlja ocenki individual'nyh riskov zdorov'ju cheloveka [Methodical approaches to calculating the probabilityof negative responses for personal human health risk assessment]. Profilakticheskaja i klinicheskaja medicina, 2015, no. 3 (56), pp. 5-11. (in Russian).

3. Ob utverzhdenii Medicinskih kriteriev opredelenija stepeni tjazhesti vreda, prichinennogo zdorov'ju cheloveka: Prikaz Ministerstva zdravoohranenija i social'nogo razvitija RF ot 24 aprelja 2008 g, № 194n [About the statement of Medical criteria of severity of the harm determination done to health of the human [An electronic resource]: The order of the Ministry of Health and Social Development of the Russian Federation from April 24, 2008. № 194H]. Sistema GARANT. Available at: http://base.garant.ru/12162210/\#ixzz2zDPH4TBv (24.01.2016). (in Russian).

4. Zaitseva N.V., May I.V., Shur P.Z. [et al]. MR 2.1.10.0033-11. Ocenka riska, svjazannogo s vozdejstviem faktorov obraza zhizni na zdorov'e naselenija. Metodicheskie rekomendacii. (Utverzhdeny Rospotrebnadzorom 31.07.2011) [MP 2.1.10.0033-11. Risk assessment connected with impact of a way of life factors to the population health: Methodical recommendations. (Are approved by Federal Service for Oversight of Consumer Protection and Welfare 31.07.2011]. Moscow, 2012. (in Russian).

5. Podrostki: riski dlja zdorov'ja i ih puti reshenija: Informacionnyj bjulleten' VOZ №345. May, 2016 g. [Teenagers: health risks and the ways of their solution: Newsletter of WHO № 345. May 2016]. Available at: http://www.who.int/mediacentre/factsheets/fs345/ru/ (15.02.2016). (in Russian). 
6. Rossijskij monitoring jekonomicheskogo polozhenija i zdorov'ja naselenija NIU-VShJe (RLMS-HSE), provodimyj Nacional'nym issledovatel'skim universitetom «Vysshaja shkola jekonomiki» i ZAO «Demoskop» pri uchastii Centra narodonaselenija Universiteta Severnoj Karoliny v Chapel Hille i Instituta sociologii RAN [The Russian monitoring of economic situation and the population health of RLMS - HSE which is carried out by National research university "Higher School of Economics" and JSC "Demoskop" with the assistance of the Center of the population of University of Northern Carolina in Tschapel Hill and Institute of sociology of the Russian Academy of Sciences]. Available at: http://www.cpc.unc.edu/projects/rlms and http://www.hse.ru/rlms (in Russian).

7. Zaitseva N.V., May I.V., Shur P.Z., Trusov P.V., Shevyreva M.P., Goncharuk N.N. Sposob opredelenija integral'nogo dopustimogo riska otdel'nyh klassov i vidov produkcii dlja zdorov'ja cheloveka. Patent na izobretenie RUS 2368322 09.01.2008 [The definition way of integrated admissible risk of separate classes and types of production for health of the human. Patent for the invention is RUS 2368322 09.01.2008]. (in Russian).

8. Surmach M.Ju. Reproduktivnoe povedenie molodezhi Belarusi i ego determinacija. Chast' 2. Planirovanie beremennosti v molodom vozraste i vlijanie povedenija zhenshhiny na zdorov'e novorozhdennogo. Mediko-gigienicheskaja gramotnost' kak faktor antiriska [Reproductive behavior of Belarusian youths and its determination Part 2. Planning of pregnancy in young age and influence of woman's behavior on the newborn's health. Medical-hygienic literacy as an anti-risk factor]. Zhurnal Grodnenskogo gosudarstvennogo medicinskogo universiteta, 2011, № 4(36), pp. 32-35. (in Russian).

9. Baranov A.A., Al'bickij V.Ju., Ivanova A.A., Terleckaja R.N., Kosova S.A. Tendencii zabolevaemosti i sostojanie zdorov'ja detskogo naselenija Rossijskoj Federacii [Trends and the health status of the child population of the Russian Federation]. Rossijskij pediatricheskij zhurnal, 2012, no. 6, pp. 4-9. (in Russian).

10.Tsinker M.Ju., Kiryanov D.A., Kamaltdinov M.R. Primenenie kompleksnogo indeksa narushenija zdorov'ja naselenija dlja ocenki populjacionnogo zdorov'ja v Permskom krae [Application of the complex index of health of the population violation for the assessment the population health in Perm Krai]. Izvestija Samarskogo nauchnogo centra Rossijskoj akademii nauk, 2013, vol.15, no. 3(6), pp. 1988-1992. (in Russian).

11.Vandelanotte C. Sugiyama T., Gardiner P., Owen N. Associations of Leisure-Time Internet and Computer Use With Overweight and Obesity, Physical Activity and Sedentary Behaviors: Cross-Sectional Study. J Med Internet Res, 2009 Jul-Sep, 11(3), e28. Published online 2009 July 27. DOI: 10.2196/jmir.1084.

12.Behavioral Risk Factor Surveillance System Questionnaire, 2014. Available at: http://www.cdc.gov/ brfss/questionnaires/pdf-ques/2014_brfss.pdf (18.03.2016).

13. Coups E.J., Ostroff J.S. A Population-based Estimate of the Prevalence of Behavioral Risk Factors Among Adult Cancer Survivors and Noncancer Controls. Prev Med, 2005 Jun, 40(6), pp. 702-711.

14.Patra J., Bhatia M., Suraweera W. [et al]. Exposure to Second-Hand Smoke and the Risk of Tuberculosis in Children and Adults: A Systematic Review and Meta-Analysis of 18 Observational Studies. PLoS Med, 2015 Jun, 12(6), e1001835. DOI: 10.1371/journal.pmed.1001835.

15.Global action plan for the prevention and control of noncommunicable diseases 2013-2020. WHO, 2014. Available at: http://apps.who.int/iris/bitstream/10665/94384/1/9789241506236_eng.pdf?ua=1 (22.02.2016).

16. Chowdhury P.P., Mawokomatanda T., F. Xu, [et al]. Chowdhury P.P. Surveillance for Certain Health Behaviors, Chronic Diseases, and Conditions, Access to Health Care, and Use of Preventive Health Services Among States and Selected Local Areas - Behavioral Risk Factor Surveillance System, United States, 2012. MMWR Surveill Summ, 2016, 65 (No. SS-4), pp. 1-142. DOI: http://dx.doi.org/10.15585/mmwr.ss6504a1.

Lebedeva-Nesevrya N.A. Methodical questions on assasment of risk associated with behavioral factors' impact on population health. Health Risk Analysis, 2016, no. 2, pp. 10-18. 